that if every zoo in the world installed a "wishing well ", which seemed to have an irresistible attraction for people to throw coins in, something like $£ 280,000$ a year could be raised for conservation.

The general feeling that the symposium, though the first of its kind, should not be the last, was voiced by Dr. Osborn at the final session, who urged that the next meeting should be in New York.

The resolution proposed by Dr. Conway for AAZPA and passed was:

That an international organisation of zoological gardens, experimental research stations, animal collections and animal traders should be developed through the agency of the IUCN Zoo Liaison Committee; that this federation should be formed, among other purposes, for developing a method of distributing certain rare animals for exhibition in co-operation with the IUCN Survival Service Commission and for co-operating with the IUCN and various national governments in the administration of this method.

\title{
SURVIVAL SERVICE COMMISSION
}

THE third meeting of the Action Group of the Survival Service Com1 mission was held at the offices of the Zoological Society of London on June 22nd to 23rd, 1964, with Mr. Peter Scott in the chair. The Commission heard Dr. Schaurte, chairman of its Rhinoceros Group, describe the plans for saving the last remnant of the Javan rhino, and Dr. Harry Lillie on the plight of the harp and hood seals, which have recently been harvested on an unprecedented scale off the Canadian coast. Dr. Lillie described the difficulties that had arisen in attempting to establish the special seal conservation panel under the International Convention for the Northwest Atlantic Fisheries. He pointed out that the estimated population of 3 million harp seals in 1949 had already been reduced by two-thirds in 1960, and if the annual kill was allowed to continue at the present rate of 300,000 to 400,000 the whole population would inevitably be wiped out. In 1964 no fewer than seventy aircraft had taken part in the annual sealing, in addition to ships. It was decided to make a direct approach to the Canadian Government to impose proper conservation practices on the sealing industry.

It was reported that the Orang-utan Recovery Scheme was launched in May with the full co-operation and sympathy of the Singapore authorities, and with funds sufficient to rescue 16 of the 50 or more smuggled baby orang-utans in Singapore and hand them over to reputable zoos.

The future of the unique Madagascar fauna and the report of M. J.-J. Petter were discussed with Professor Bourlière, who reported that this year one of the best nature reserves in the island had been declassified. Special attention was given, and appropriate action suggested, for ten birds, including the Japanese crested ibis, the Hawaian duck and the noisy scrub bird, and ten mammals, including the blue whale, the Indian lion, Hunter's antelope and the Zanzibar colobus monkey.

\section{Mexico Investigates Turtle Protection}

The Director-General of Fisheries in Mexico, Admiral Antonio Vazquez del Mercado, replying to the request of the FPS that the recently discovered breeding ground of the Atlantic Ridley turtle should be protected, says that the question of the turtle's conservation is being studied by the National Institute for Biological and Fisheries Research in Mexico. 